\title{
SUPERSOLIDUS SINTERING OF Cr PREALLOYED STEELS BY INDUCTIVE HEATING
}

\author{
C. Gierl-Mayer, M. C. Huemer, H. Danninger, M. Dlapka, G. Stetina, R. Ratzi
}

Dedicated to the memory of Dr. Gert Leitner (1940-2019), a pioneer of thermal analysis and induction sintering

\begin{abstract}
For powder metallurgy products, high density is an essential requirements to obtain maximum mechanical properties. Here, supersolidus liquid phase sintering (SSPLS) is an effective means to attain high sintered density, as known from PM high speed steels. In the present work it is shown that this technique can also be applied to $\mathrm{Cr}$ prealloyed low alloy steel grades. Supersolidus sintering through indirect heating requires precise control of temperature and also the atmosphere, to avoid uncontrolled changes of the carbon level. Higher $C$ contents are beneficial here since they enable lower temperatures and result in wider temperature windows for sintering. The temperatures necessary for SSLPS at moderate $C$ levels are fairly high for standard sintering furnaces, therefore induction sintering was studied in this work. It showed that, as was to be expected, also here precise temperature control is required, but for any carbon level tested a sintering temperature could be identified that yielded high sintered density and good shape retention. The high density attained, in combination with the very high temperatures, results in pronounced grain growth, this process no more being inhibited by the presence of pores, which is undesirable but can however be remedied by suitable heat treatment.
\end{abstract}

Keywords: supersolidus sintering, induction sintering, microstructure

\section{INTRODUCTION}

Complex-shaped powder metallurgy precision parts have gained high industrial and economical importance, especially in the automotive industry. Due to the variety of manufacturing methods, alloying technique and alloying elements, the required properties can be tailored specifically, with significantly more flexibility than with wrought steels. The main property that determines the mechanical property is the density level, which typically results from the compacted component. For highly loaded components it is frequently essential to produce PM steels with low to very low residual porosity, which is difficult to obtain by pressing, intolerably high compacting pressures being required. On the other hand, increasing the density can be attained inter alia by activated sintering, in particular liquid phase sintering [1,2].

Christian Gierl-Mayer, Marie-Christine Huemer, Herbert Danninger: Institute of Chemical Technologies and Analytics, TU Wien. Vienna, Austria

Magdalena Dlapka, Gerold Stetina: Miba Sinter Austria GmbH, Dr. Mitterbauer-Str.1, AT-4655 Vorchdorf, Austria

Raimund Ratzi: MIBA AG, AT-4665 Laakirchen, Austria 
Liquid phase sintering can be classified in two variants: sintering with a persistent liquid phase, which is present throughout the whole sintering process in virtually the same amount, and on the other hand a transient liquid phase that intermediately appears for a short time $[3,4]$. For attaining densification during sintering the persistent variant is better suited, as evident from sintering e.g. of hardmetals or W heavy alloys. Supersolidus liquid phase sintering (SPLS) is a special case of liquid phase sintering, first published by Lund and Bala [5]. Thereby an alloy powder, heated to a temperature between the liquidus and the solidus, is used. The liquid is formed inside the particles, and the resulting densifying process can be described as a rapid viscose flow through the effect of capillary forces. $[\underline{6,7,8]}$.

As typical for SSLPS, an accurate control of the sintering temperature is required to avoid oversintering which occurs in presence of too much liquid and in consequence leads to distortion of the compacts and to undesirable microstructures; nevertheless a critical amount of liquid is necessary to promote full densification [9,10]. Therefore, the application of SSLPS so far has been limited to a few materials, mainly high speed steels $[11,12]$, although studies have been done also with other materials such as e.g. brass [13]. The aim of the present investigation is to show that the SSPLS process can also be adopted to $\mathrm{Cr}$ prealloyed low alloy steel grades. For this purpose, sintering of powder compacts was done conventionally in a dilatometer and secondly, because of the fairly high temperatures necessary at moderate $\mathrm{C}$ levels, by induction sintering of presintered specimens, inductive heating being better suited for very high temperatures.

Induction sintering, both as a variant of direct sintering or indirectly using a susceptor $[14,15]$, has been studied frequently, in particular for hardmetals, but also for PM steels $[16, \overline{17}]$, but so far the industrial applications are very limited, similar as for other "flash" sintering techniques such as microwave sintering. One reason is that sintering involves not only densification and formation of metallic bridges, but also chemical processes such as removal of the "natural" oxygen have to be considered. If however these processes could be separated from the "densification step" and moved into a preceding solid state sintering process, a short-time induction sintering can be expected to perform the required densification without problems from gas-forming processes, and this was investigated here.

\section{EXPERIMENTAL PROCEDURE}

The first experiments on Supersolidus Liquid Phase Sintering of chromium containing steels were carried out using a pushrod dilatometer as a minisize, precisely controllable sintering furnace. As a preliminary study, prealloyed powder AstaloyCrM, a water atomized steel powder grade from Höganäs AB, Sweden, was mixed with $1.0 \%$ carbon (natural graphite Kropfmühl UF4) in a turbula mixer for 60 minutes (all concentrations are given in $\mathrm{wt} \%$ ). As typical for prealloyed powders, both alloying elements, chromium (3.0\%) and molybdenum (0.5\%), were distributed homogeneously in the material. After blending, the powder mix was compacted at $600 \mathrm{MPa}$ to Charpy samples (ISO 5754). The following sintering process was accomplished in a pushrod dilatometer (Netzsch 402) with a heating rate of $10 \mathrm{~K} / \mathrm{min}$, subsequent isothermal sintering at $1365^{\circ} \mathrm{C}$ for 1 hour and cooling once more with a rate of $10 \mathrm{~K} / \mathrm{min}$, the atmosphere being rotary pump vacuum $(8 \cdot 10-3$ mbar at room temperature and $2 \cdot 10-2$ mbar at sintering temperature). For characterization, the dimensional change, the Archimedes density, the unnotched Charpy impact energy and the Vickers hardness of the sample were measured. 
Based on these results, further experiments were performed using induction sintering. Specimens dewaxed/presintered (in fact solid state sintered) in a tube furnace at $1250^{\circ} \mathrm{C}$ were inductively high temperature sintered for a short time.

AstaloyCrM powders were blended with $0.6,0.7,0.8,0.9,1.0,1.1,1.2$ and $1.4 \% \mathrm{C}$ and once more pressed to Charpy bars at $600 \mathrm{MPa}$. In the first step, a dewaxing/presintering/deoxidizing step was done as described above in atmosphere $\mathrm{N}_{2}$ $10 \% \mathrm{H}_{2}$ (both purity 5.0). Pieces of the pre-sintered samples were cut, transferred into a graphite crucible and heated with a rate of $400 \mathrm{~K} / \mathrm{min}$ in a medium frequency induction furnace (pure $\mathrm{N}_{2}$, quality 5.0 ) to $1310,1340,1370,1400$ and $1430^{\circ} \mathrm{C}$. The temperature control was performed by a pyrometer which was placed in such a way that it was possible to measure the temperature on the base plate of the crucible. The samples were isothermally held at these temperatures for $5 \mathrm{~min}$, and then a cooling rate of $600 \mathrm{~K} / \mathrm{min}$ was adjusted (which could however be maintained only in the higher temperature range). A nitrogen pressure of 800 mbar, slightly below ambient pressure, was necessary to keep the furnace gas tight.

On the sintered specimens, the density was measured through Archimedes' principle (water displacement). Then, cross-sections of the samples were prepared for light microscopic investigations (unetched and etched), and the Vickers hardness, HV30, was measured.

\section{RESULTS AND DISCUSSION}

\section{Sintering in the dilatometer}

In Table 1 the properties of the conventionally sintered AstaloyCrM $+1.0 \% \mathrm{C}$ (admixed) sample are listed. As shown here, a density of $7.76 \mathrm{~g} / \mathrm{cm}^{3}$ could be reached without compromising the dimensional stability, the shape of the bars remaining precisely rectangular. Due to the moderate heating rate $(10 \mathrm{~K} / \mathrm{min}$ ) of the dilatometer (tube furnace: $60-100 \mathrm{~K} / \mathrm{min}$ ) which enables a slow, controlled and uniform heat penetration, no gas outbursts occurred; the degassing/deoxidizing process was completed before densification had proceeded so far that the pore channels were closed.

Tab.1. Measured properties (as sintered) of the AstaloyCrM+ $1.0 \% \mathrm{C}$ impact test bar, sintered in the dilatometer at $1365^{\circ} \mathrm{C}, 10 \mathrm{~K} / \mathrm{min}-60 \mathrm{~min}-10 \mathrm{~K} / \mathrm{min}$, vacuum

\begin{tabular}{|c|c|c|}
\hline Sintering Temperature & {$\left[{ }^{\circ} \mathrm{C}\right]$} & 1365 \\
\hline Density & {$\left[\mathrm{g} / \mathrm{cm}^{3}\right]$} & 7.76 \\
\hline Dimensional Change & {$[\%$ lin. $]$} & -3.35 \\
\hline Impact energy & {$\left[\mathrm{J} / \mathrm{cm}^{2}\right]$} & 8.2 \\
\hline Hardness & {$[\mathrm{HV} 30]$} & 412 \\
\hline
\end{tabular}

For characterization of the structure, a cross section of the sample was prepared, polished and photographed; (see Figure 1a). The sample is highly dense, just a few, partly small, pores are visible. During SSLPS the grains seem to coarsen a lot, which is not surprising regarding the high temperature and very low porosity (see [18]); the low impact energy can be attributed in part to this coarse microstructure.

For revealing the matrix microstructure, the section was etched with $3 \%$ Nital; see Figure 1b. A network of proeutectoid cementite seemed to have been formed at the grain boundaries during SSPLS, in addition to a predominantly bainitic/martensitic 
microstructure. This results in quite high values for the Vickers macrohardness (see Table 1) but a low impact energy, the grain coarsening described above enhancing the adverse effect of proeutectoid cementite on the impact behavior.
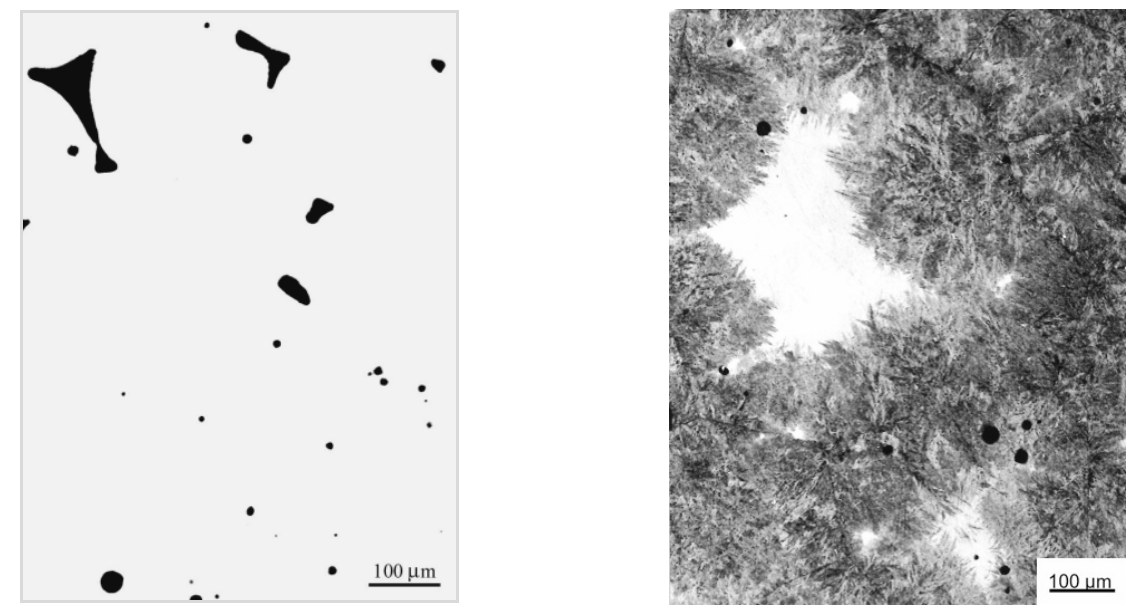

Fig.1. AstaloyCrM $+1.0 \% \mathrm{C}$, sintered in the dilatometer at $1365^{\circ} \mathrm{C}, 10 \mathrm{~K} / \mathrm{min}-60 \mathrm{~min}-$ $10 \mathrm{~K} / \mathrm{min}$, vacuum; (a) unetched, (b) etched with $3 \%$ Nital.

In any case, these preliminary results have shown that by SSLPS, pronounced densification can also be attained with chromium containing low alloy steels, but a subsequent heat treatment step for grain refinement and dissolution of proeutectoid cementite is regarded necessary.

\section{Presintering and final induction sintering}

Based on the promising results of the first indirect sintering runs done at $1365^{\circ} \mathrm{C}$, the first temperature set for induction sintering was $1370^{\circ} \mathrm{C}$. In Figure 2 the different samples containing varying amounts of admixed carbon ranging from 0.6 to $1.4 \% \mathrm{C}$, are shown after the induction sintering step ( 5 min hold).

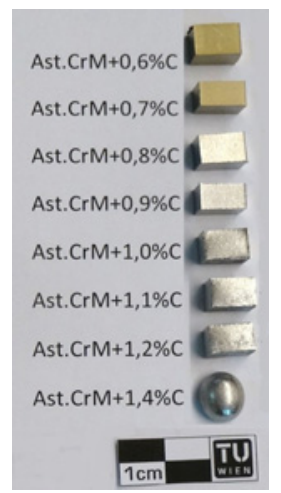

Fig.2. AstaloyCrM+x\%C (x...0.6-1.4), presintered and then induction sintered, $400 \mathrm{~K} / \mathrm{min}$ $5 \mathrm{~min}-600 \mathrm{~K} / \mathrm{min}, 800 \mathrm{mbar}_{2}, 1370^{\circ} \mathrm{C}$. 
As can be clearly seen, the samples with $0.6-0.9 \% \mathrm{C}_{\text {admixed }}$ could be sintered to products with stable shapes. For the ones with higher carbon contents the temperature was definitely too high, too much liquid phase was formed, with adverse effect on shape retention. At this temperature, satisfactory SSPLS could be achieved for $0.9 \% \mathrm{C}$, as indicated by high shrinkage and metallic finish without losing shape.

Based on these first sintering results, the samples containing 0.6, 0.7, 0.8, $0.9 \% \mathrm{C}_{\text {admixed }}$ were sintered at higher temperatures (within $30^{\circ} \mathrm{C}$ steps), and the other samples with $1.0,1.1,1.2$ and $1.4 \% \mathrm{C}$ at lower temperatures, also in $30^{\circ} \mathrm{C}$ steps. In Table 2 the sample matrix for sintering at different temperatures is listed. In green, the applied induction sintering temperatures (until loss of shape takes place) for the respective carbon contents are highlighted.

Tab.2. Sample matrix, applied induction sintering temperature $\left[{ }^{\circ} \mathrm{C}\right]$ for AstaloyCrM $+\mathrm{x} \% \mathrm{C}_{\text {admixed }}(\mathrm{x} \ldots . .0 .6-1.4)$

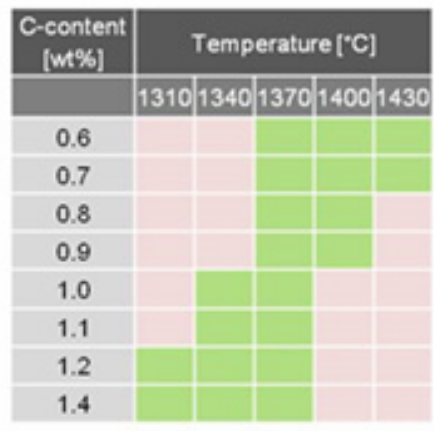

For all compositions a suitable induction sintering temperature, with high shrinkage and densification and retention of the shape at the same time, could be defined. For a better overview the determined sintered density $\left(\rho_{\text {sinter }}\right.$ in $\left.\mathrm{g} / \mathrm{cm}^{3}\right)$ is plotted against the sintering temperature for the compositions AstaloyCrM+0.6, 1.0 and $1.4 \% \mathrm{C}$; see Figure 3 .

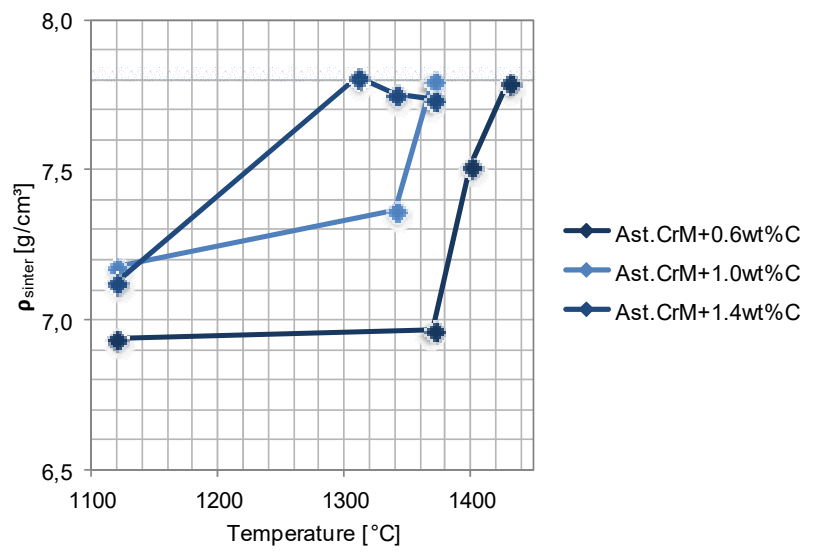

Fig.3. Sintered density vs. sintering temperature of AstaloyCrM+0.6, 1.0 and $1.4 \mathrm{wt} \% \mathrm{C}$; after induction sintering, $400 \mathrm{~K} / \mathrm{min}-5 \mathrm{~min}-600 \mathrm{~K} / \mathrm{min}, 800 \mathrm{mbar}_{2}$, at different temperatures. 
The theoretical (pore-free) density is marked in light blue in the graphic; it is shown that all specimens with different compositions can be sintered to almost full density if the correct temperature is chosen. For $0.6 \% \mathrm{C}$, even at a sintering temperature of $1370^{\circ} \mathrm{C}$ in the induction furnace hardly any densification occurs; the SSPLS process starts at markedly higher temperatures $\left(1400^{\circ} \mathrm{C}\right)$. For AstaloyCrM $+1.4 \% \mathrm{C}$, on the other hand, a sintered density of $7.8 \mathrm{~g} / \mathrm{cm}^{3}$ can be attained already at $1310^{\circ} \mathrm{C}$, while above this temperature oversintering occurs which results either in swelling of the sample or, at still higher temperatures, in complete melting.

In Figure 4 the unetched cross sections of the AstaloyCrM samples with the lowest carbon content $\left(0.6 \% \mathrm{C}_{\text {admixed }}\right)$ after all sintering steps are displayed (magnification $\left.50 \mathrm{x}\right)$. In the specimen (a), induction sintered at $1370^{\circ} \mathrm{C}$, considerable porosity can be detected, while after sintering at $1400^{\circ} \mathrm{C}$, only a few small isolated pores can be found (b), i.e. SPLS is effective at this temperature. After sintering at $1430^{\circ} \mathrm{C}$ (c) huge pores were found sporadically distributed within the entire component. Explanations for that are on one hand too much liquid phase, and on the other hand a densification that has started in the surface zone before the gaseous products of carbothermal oxide reduction were removed, which results in these gas outbursts and in stabilizing large pores which act as sinks for the pore space from smaller pores, following the Ostwald ripening mechanism.

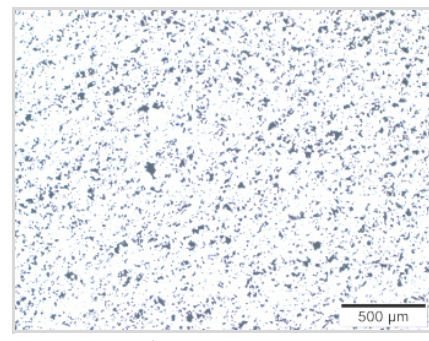

a) $1370^{\circ} \mathrm{C}$

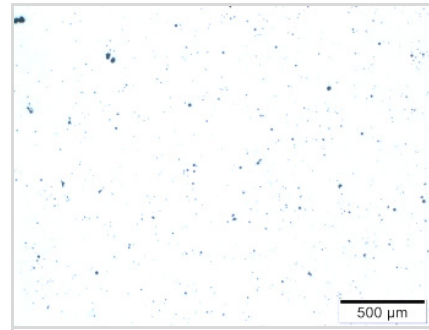

b) $1400^{\circ} \mathrm{C}$

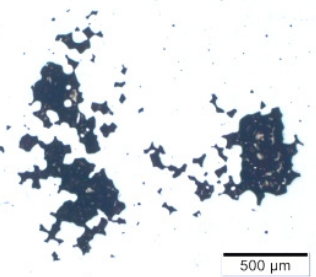

c) $1430^{\circ} \mathrm{C}$

Fig.4. AstaloyCrM $+0.6 \% \mathrm{C}$ induction sintered at different temperatures, $400 \mathrm{~K} / \mathrm{min}-5 \mathrm{~min}$ $600 \mathrm{~K} / \mathrm{min}, 800 \mathrm{mbar} \mathrm{N} 2,50 \mathrm{x}$.

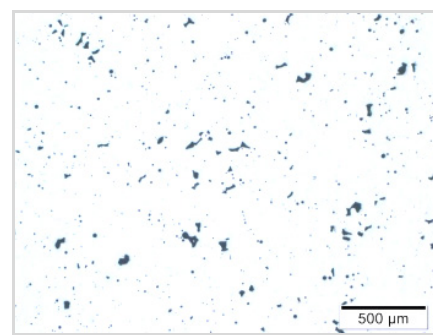

a) $1310^{\circ} \mathrm{C}$

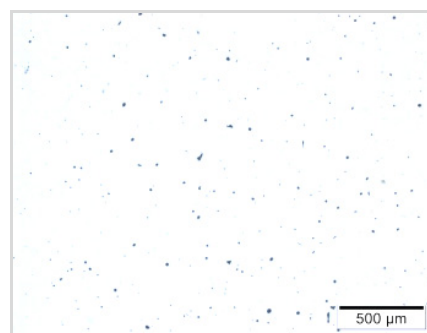

b) $1340^{\circ} \mathrm{C}$

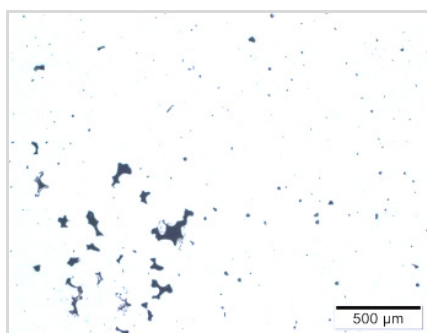

c) $1370^{\circ} \mathrm{C}$

Fig.5. AstaloyCrM $+1.4 \% \mathrm{C}$, induction sintered at different temperatures, $400 \mathrm{~K} / \mathrm{min}-5 \mathrm{~min}$ - $600 \mathrm{~K} / \mathrm{min}, 800 \mathrm{mbar}_{2}, 50 \mathrm{x}$.

In Figure 5 the polished cross sections of the sintered AstaloyCrM pieces with the highest carbon content $\left(1.4 \% \mathrm{C}_{\text {admixed }}\right)$ are shown as examples. After induction sintering at $1310^{\circ} \mathrm{C}$ an increase of density can be observed compared to e.g. Figure 4a, but also grain growth, this was already shown by the results of the previous study. The microstructure of the sample sintered at $1340^{\circ} \mathrm{C}$ (c) looks better/denser, but this piece could not be sintered 
without losing its shape, and the same holds for $1370^{\circ} \mathrm{C}$, because of oversintering. Also here, coarse pores appear, although not as massively as shown in Figure 4c; probably the lower temperature results in less pronounced reduction of stable oxides.

In Figure 6 and Figure 7 Nital etched microstructures are shown, again exemplary for the two compositions AstaloyCrM+0.6 and 1.4\% (magnification 200x).

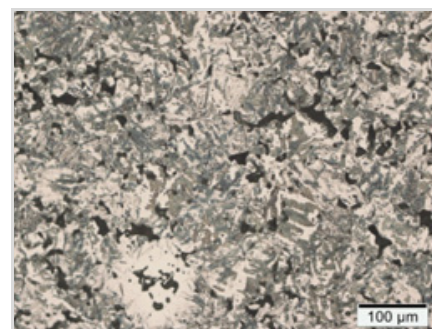

a) $1370^{\circ} \mathrm{C}$

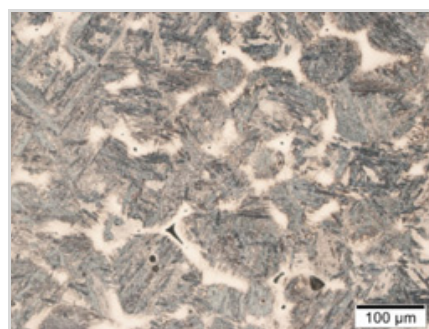

b) $1400^{\circ} \mathrm{C}$

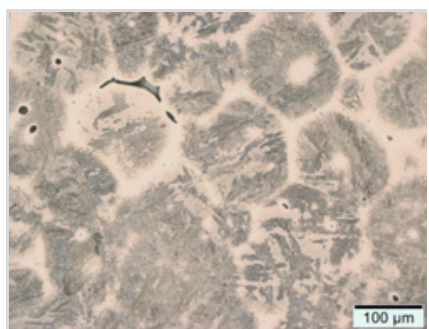

c) $1430^{\circ} \mathrm{C}$

Fig.6. AstaloyCrM $+0.6 \% \mathrm{C}$ induction sintered at different temperatures, $400 \mathrm{~K} / \mathrm{min}-5 \mathrm{~min}$ - $600 \mathrm{~K} / \mathrm{min}, 800$ mbar $\mathrm{N}_{2}{ }^{5} 50 \mathrm{x}$, Nital etched.

After induction sintering, bainitic microstructure is found due to the slower cooling rate of the furnace at lower temperatures whereby bainite can be stabilized. Coinciding with pronounced densification, strong grain growth can be observed as well. For grain refinement a subsequent heat treatment, similar to normalizing of cast steel components, would be useful.

For AstaloyCrM $+1.4 \% \mathrm{C}$, induction sintering results in a clearly visible network of proeutectoid cementite formed at the grain boundaries during SSPLS; the same had been discovered after the preliminary sintering in the dilatometer (see above).

Furthermore, grain growth could be detected for this composition, already starting at $1310^{\circ} \mathrm{C}$ (Fig.7a) because of the decrease of porosity which normally prevents grain growth [13]. Deceptively, the specimens of the composition AstaloyCrM+1.4\%C induction sintered at 1340 (c) and $1370^{\circ} \mathrm{C}$ (d) seem to have quite attractive densities, however both samples were totally oversintered and had lost their shape. The same trends were observed for all other compositions, just the temperature level for optimum sintering varying with carbon content.

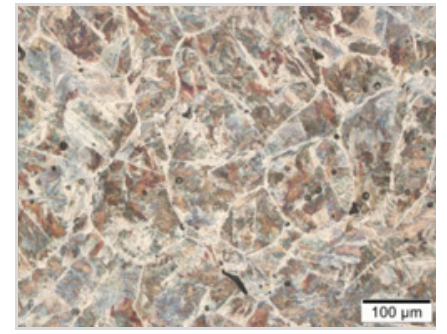

a) $1310^{\circ} \mathrm{C}$

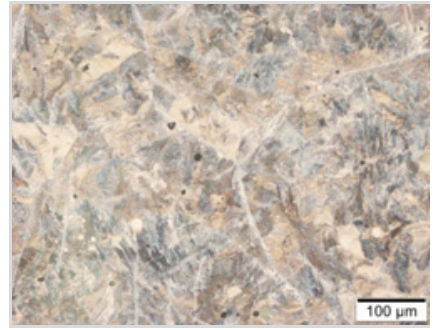

b) $1340^{\circ} \mathrm{C}$

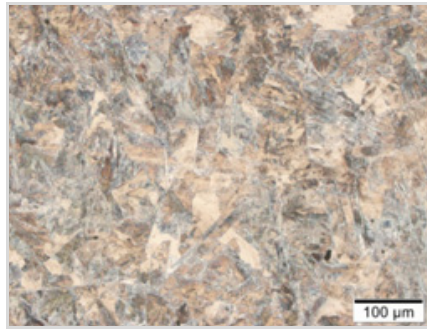

c) $1370^{\circ} \mathrm{C}$

Fig.7. AstaloyCrM $+1.4 \% \mathrm{C}$ induction sintered at different temperatures, $400 \mathrm{~K} / \mathrm{min}-5 \mathrm{~min}$ - $600 \mathrm{~K} / \mathrm{min}, 800$ mbar $\mathrm{N}_{2}, 50 \mathrm{x}$, Nital etched.

For further analysis the macrohardness (HV30) of all samples was measured to observe densification effects and consequently the increase of hardness. As representative 
examples the results of the samples AstaloyCrM+0.6, 1.0 and $1.4 \% \mathrm{C}$ are depicted in the following histograms (Figure 8).

Analysis of the hardness trends induces the conclusion that the process of densification due to supersolidus liquid phase sintering can be described quite well by hardness measurements, but no statements concerning oversintering can be produced.

The HV30 values of AstaloyCrM $+1.4 \% \mathrm{C}$ show quite well that a temperature above $1310^{\circ} \mathrm{C}$ does not lead to higher densities, already the material sintered with $1310^{\circ} \mathrm{C}$ has hardly any porosity left. At the same time no hardness loss was measured although the samples lost their shape at higher temperatures. The same applies for Ast.CrM $+1.0 \%$, in which case the highest density could be obtained after induction sintering at $1370^{\circ} \mathrm{C}$, but this sample was not sintered dimensionally stable. As shown in Fig.8 and confirmed by micrographs, the presintered AstaloyCrM-0.6wt\%C sample has quite a high hardness (because of existing martensitic structures). After sintering at $1370^{\circ} \mathrm{C}$ a drop of hardness could be noticed because of the "low" cooling rate, but at $1400^{\circ} \mathrm{C}$, as SSLPS occurred, an increase of hardness was recorded again. In this case the oversintering of the sample could be detected; the material sintered at $1430^{\circ} \mathrm{C}$ shows a low hardness value again.

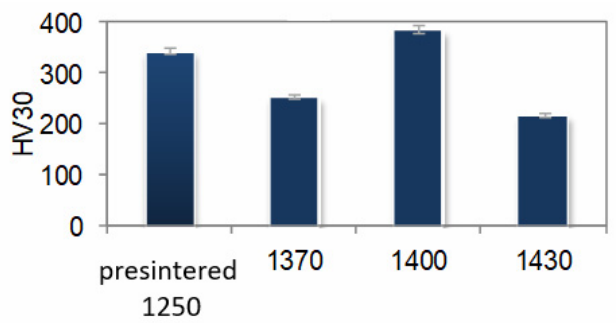

a) AstaloyCrM+0.6wt $\% \mathrm{C}$

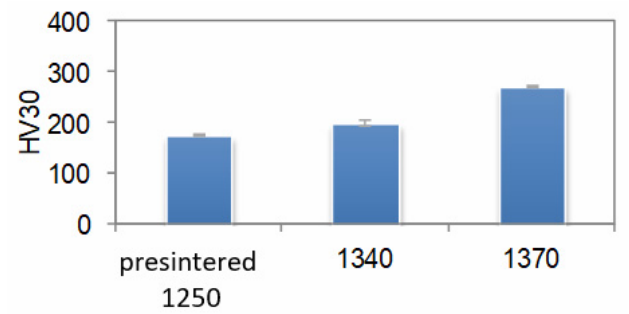

b) AstaloyCrM+1.0wt $\% \mathrm{C}$

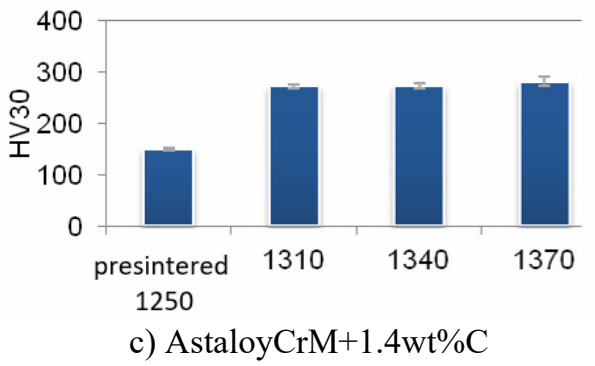

Fig. 8. Hardness HV30 of AstaloyCrM-samples, induction sintering, $400 \mathrm{~K} / \mathrm{min}-5 \mathrm{~min}$ $600 \mathrm{~K} / \mathrm{min}, 800 \mathrm{mbar}_{2}$; as a reference, hardness from presintered samples $\left(1250^{\circ} \mathrm{C}\right)$ is given.

\section{CONCLUSIONS}

The preliminary sintering experiment done in a dilatometer on $\mathrm{Cr}$-Mo prealloyed AstaloyCrM with a quite high carbon content of $1.0 \%$ showed that high densification by SSPLS can be also attained with chromium containing low alloy steels. On the negative side, grain coarsening and a network of proeutectoid cementite could be observed as well.

Further investigations have been performed with induction sintering, which enables attaining the high temperatures necessary for SSLPS more easily. Sintering was done in a two-step-process, first conventional solid state sintering in a pusher furnace and then induction SSLPS for a short time. This was applied for a carbon content that was 
varied from 0.6 to $1.4 \%$, whereby supersolidus liquid phase sintering occurred for all compositions, though at different temperatures. A suitable induction sintering temperature, resulting in high shrinkage and shape retention at the same time, could be found for all compositions, though at different levels. Micrographs (polished and etched) showed that above a critical temperature huge pores were found that are statistically distributed over the entire component, due to concurrent densification and formation of gas products, which results in gas outbursts and damage to the specimens. Grain growth was detected for all compositions, starting at temperatures where pronounced densification through SSPLS occurs, because of the dramatic decrease of porosity which normally prevents grain coarsening very effectively in sintered steels. For higher carbon contents a network of proeutectoid cementite was formed at the grain boundaries during SSPLS; similar to that observed after sintering in the dilatometer. For both problems, grain coarsening and proeutectoid cementite, a suitable heat treatment would be the remedy, as known e.g. from casting of steels.

In general it can be stated that supersolidus liquid phase sintering can be applied for chromium steels, leading to almost full density while the specimen shape is retained. Both conventional and induction heating can be applied, the latter being an attractive solution for steels with lower $\mathrm{C}$ levels that require very high sintering temperatures. The most important items are selecting and maintaining the optimum sintering temperature for the given carbon level. Furthermore, attaining oxygen removal by a solid state sintering process before the densifying induction process was found to eliminate the formation of gas pores and blisters if induction sintering was done in the proper temperature interval.

\section{REFERENCES}

[1] German, RM.: Sintering Theory and Practice. New York : John Wiley \& Sons, Inc., 1996

[2] Huemer, M., Gierl-Mayer, C., Danninger, H. In: PM2014 World Congress on Powder Metallurgy \& Particulate Materials. Orlando, 2014

[3] Schatt, W.: Sintervorgänge. Düsseldorf : VDI Verlag, 1992

[4] German, RM.: Int. J. Powder Metall. \& Powder Technol., vol. 19, 1983, no. 4, p. 277

[5] Gierl-Mayer, C., Danninger, H., De Oro, R., Hryha, E. In: Advances in Powder Metallurgy and Part. Materials 2014. Proceedings of World PM Orlando, Florida May 18-22 2015. Eds. RA. Chernenkoff, WB. James, p. 05-74

[6] Lund, JA., Bala, SR.: Powder Metall., vol. 6, 1974, p. 409

[7] German, RM.: Int. J. Powder Met., vol. 26, 1990, p. 23

[8] Liu, J., Upadhyaya, A., German, RM.: Metallurg. \& Mat. Trans. A, vol. 30A, 1999, no. 8, p. 2209

[9] Danninger, H., Gierl, C.: Materials Chemistry and Physics, vol. 67, 2001, no. 1-3, p. 49

[10] Liu, J., Lal, A., German, RM.: Acta Mat., vol. 47, 1999, no. 18, p. 4615

[11] Huppmann, WJ.: Int. J. Powder Metall. \& Powder Technol., vol. 21, 1985, no. 3, p. 183

[12] Gierl-Mayer, C.: Herstellung von hochdichten PM-Präzisionsteilen durch optimierte Sinterverfahren. Ph.D Thesis. Wien : TU, 2000

[13] Mohammadzadeh, A., Azadbeh, M., Danninger, H.: Powder Metallurgy, vol. 58, 2015, no. 2 , p. 123

[14] Schatt, W., Wieters, K-P., Kieback, B.: Pulvermetallurgie - Technologien und Werkstoffe, 2., bearbeitet Auflage. Berlin, Heidelberg, New York : Springer Verlag, 2007

[15] Upadhyaya, A., Upadhyaya, GS.: Powder Metallurgy - Science, Technology and Materials. Hyderabad, India : Universities Press, 2011 
[16] Hermel, W., Leitner, G., Krumphold, R.: Powder Metallurgy, vol. 23, 1980, no. 3, p. 130

[17] Šalak, A.: Ferrous Powder Metallurgy. Cambridge : International Science Publishing, 1997

[18] Dlapka, M., Strobl, S., Danninger, H., Gierl, C.: Practical Metallography, vol. 47, 2010, no. 12 , p. 686 